\title{
A EDUCAÇÃO ESPECIAL NO CONTEXTO DA SOCIEDADE INCLUSIVA: CONSTRUINDO SENTIDOS SOBRE A APRENDIZAGEM DE CRIANÇAS COM DEFICIÊNCIAS
}

\author{
Maria Helena De Oliveira ${ }^{1}$ \\ Francisco Renato Lima ${ }^{2}$
}

\begin{abstract}
RESUMO: O discurso sobre uma educação inclusiva é parte de um movimento de todos que fazem a educação, e não apenas da Educação Especial. Esta, como uma modalidade de educação escolar, tem sido objeto de estudos e de pesquisas gerando importantes debates com vários estudiosos, independente da área em que atuam, constituindo assim, um campo interdisciplinar de discussão, com vistas, sobretudo, a aplicação de propostas que viabilizem melhorias no ensino de crianças com deficiências. Com base nisso, apresenta-se este estudo bibliográfico, de natureza qualitativa, baseado em aportes teórico-legais, como: a Lei de Diretrizes e Bases da Educação Nacional - LBD 9.394/96, as Diretrizes Nacionais para a Educação Especial na Educação Básica (2001) e a Política Nacional de Educação Especial na Perspectiva da Educação Inclusiva (2008); aliados a leitura de autores, como: Batista (2006), Carvalho (2003), Ferreira; Guimarães (2003), Oliveira (1993), Ropoli (2010), entre outros. Dessa discussão, tem-se o entendimento de que a Educação Especial, como modalidade de ensino da educação básica, faz parte de uma concepção de educação e sociedade inclusiva, a qual estrutura as políticas sociais do século XXI. Essa perspectiva inclusiva tem por objetivo romper barreiras e transformar a educação em espaço de igualdade para todas as pessoas, dando-lhes o direito de terem oportunidades iguais, respeitando e valorizando as diferenças que os singularizam nas interações com os outros, constituindo assim, oportunidades de livre expressão e manifestação das potencialidades dos sujeitos, tornando-os ativos no processo de aprendizagem.
\end{abstract}

PALAVRAS-CHAVE: Educação Inclusiva. Educação Especial. Crianças com deficiências. Prática Pedagógica.

\begin{abstract}
The speech on inclusive education is part of a movement of all who make education, and not just the Special Education. This, as a form of school education, has been the subject of studies and research generated important discussions with several scholars, regardless of the area in which they operate, thus an interdisciplinary field of discussion, with a view, above all, the implementation of proposals enable improvements in teaching children with disabilities. Based on this, we present this bibliographic study, qualitative, based on theoretical and legal contributions, such as the Law of Guidelines and Bases of Education - LBD 9.394 / 96, the National Guidelines for Special Education in Basic Education (2001) and the National Special Education Policy in Perspective of Inclusive Education (2008); Allied reading authors such as: Batista (2006), Carvalho (2003), Ferreira; Guimarães (2003), Oliveira (1993), Ropoli (2010), among others. From this discussion, it has been the understanding that the Special Education as basic education teaching mode, is part of a concept of education and inclusive society that the social policy framework of the XXI century. This inclusive approach aims to break down barriers

\footnotetext{
${ }^{1}$ Graduada em Letras - Português (UESPI). Especialista em Docência do Ensino Superior (FAERPI). Especialista em LIBRAS: Língua Brasileira de Sinais (IFPI). Mestre em Letras - Estudos da Linguagem (UFPI). Professora de Língua Portuguesa na Secretaria Estadual de Educação e Cultura (SEDUC-PI). Email: revisora helena@hotmail.com ${ }^{2}$ Graduado em Pedagogia (FSA) e em Letras - Português (INET). Especialista em Neuropsicopedagogia Clínica e Educação Especial (IESM). Especialista em Docência para o Ensino Superior (IESM). Mestre em Letras - Estudos da Linguagem (UFPI). Com experiência docente na rede pública e privada de ensino básico e superior. Email: fcorenatolima@hotmail.com
} 
and make equal space in education for all people, giving them the right to have equal opportunities, respecting and valuing the differences that individualize in interactions with others, thus constituting, opportunities free expression and manifestation of the potential of individuals, making them active in the learning process.

KEYWORDS: Inclusive Education. Special Education. Children with disabilities. Teaching practice.

\section{CONSIDERAÇÕES INICIAIS}

A escola da contemporaneidade é o espaço da diferença e da confluência de culturas e da diversidade. Diante desse quadro social, emerge a necessidade de ampliação e redimensão dos saberes e das práticas educativas, afim de que esta escola constitua-se como um espaço de reconhecimento e valorização dessas diferenças, conforme os argumentos que sustentam o discurso da inclusão social, como princípio básico de garantia dos direitos do cidadão.

No cenário nacional existem diversas leis que arregimentam essas propostas. Dentre elas, destaca-se a Lei de Diretrizes e Bases da Educação Nacional, LDB 9.394/96 desenvolvida sob as normas da Lei Maior (Constituição da República Federativa do Brasil, de 1988) e que destaca o direito de educação para todos. Há também organismos internacionais, que por meio de Conferências Internacionais, onde se reúnem vários países, têm por objetivo de reforçar a ideia de inclusão social e, portanto educacional.

Ilustramos essa questão, listando, por exemplo:

i) a Convenção dos Direitos da Criança, adotada pela Assembleia Geral nas Nações Unidas em 20 de Novembro de 1989 e ratificada por Portugal em 21 de Setembro de 1990;

ii) a Declaração de Jomtien, elaborada no Conferência Mundial sobre Educação para Todos, realizada na cidade de Jomtien, na Tailândia, em 1990;

iii) a Cúpula Mundial das Crianças, ocorrida nos dias 29 e 30 de setembro de 1990, em Nova York;

iv) a Declaração de Salamanca, resultante da Conferência Mundial sobre Necessidades Educativas, realizada em Salamanca, Espanha, de 07 a 10 de junho de 1994;

v) a Carta para o Terceiro Milênio, escrita e aprovada no dia 9 de setembro de 1999, em Londres - Grã-Bretanha;

vi) a Convenção de Guatemala, resultante da Convenção Interamericana para a Eliminação de Todas as Formas de Discriminação Contra as Pessoas Portadoras de Deficiência, aprovada pelo Conselho Permanente na sessão realizada em de 28 de maio de 1999; 
vii) a Declaração Internacional de Montreal, aprovada em 5 de junho de 2001 pelo Congresso Internacional e Sociedade Inclusiva, realizado em Montreal, Quebec, Canadá.

Esses e muitos outros documentos têm fundamentado as discussões e concepções que orientam as práticas educativas, alicerçado a ideia de que todos possuem o mesmo direito: o de frequentar a mesma escola, independente de raça, cor, religião, sexo ou qualquer tipo de deficiência. Essas orientações constituem-se como "substância visível da política" (MULLER; SUREL, 2002, p. 14), constituindo um movimento social que busca transcender os limites da teoria e materializar ações que promovam a inclusão social.

Mediante esse contexto, a escola deve desenvolver, a partir dessa legislação vigente, condições de acesso e permanência do aluno na escola, através de propostas pedagógicas que promovam a interação entre os alunos e o contexto social, o que pressupõe uma ressignificação das concepções de currículo, gestão e metodologias de ensino que efetivamente, promovam a inclusão do aluno. Segundo Carvalho:

A proposta da educação inclusiva não representa um fim em si mesmo, como se, estabelecidas certas diretrizes organizacionais, a escola melhorasse, num passe de mágica. Muito mais do que isso, pretende-se, a partir da análise de como tem funcionado o nosso sistema educacional, identificar as barreiras existentes para a aprendizagem dos alunos, com vista às providências políticas, técnicas e administrativas que permitam enfrentá-las e removê-las. Pretende-se identificar processos que aumentem a participação de todos os alunos, reduzindo-lhes a exclusão na escola e garantindo-lhes sucesso em sua aprendizagem, além do desenvolvimento da autoestima (CARVALHO, 2003, p. 149).

Diante dessa abordagem, percebe-se que um dos principais objetivos da escola inclusiva é reduzir a exclusão social através dos seus mecanismos, oferecendo uma educação de qualidade a todos, transformando cada vez mais a realidade da comunidade ao seu redor. É nesta perspectiva, portanto, que se situa a modalidade Educação Especial, que dentro de um contexto de sociedade inclusiva busca organizar ambientes favoráveis para o desenvolvimento de práticas pedagógicas que reconheçam, compreendam e valorize os diferentes ritmos de aprendizagem dos sujeitos, que se expressam de maneira singular devido a fatores biológicos, culturais e socioeconômicos, exigindo do professor, a necessidade de envolver a todos no processo ensino aprendizagem.

Considerando essa proposta, discutimos sobre as possibilidades de realização de práticas pedagógicas neste sentido, que propiciem o bem estar e o desenvolvimento dos alunos, construindo assim, uma aprendizagem mais significativa, em que os educandos com necessidades especiais aprendam a observar, analisar, comparar, dialogar, raciocinar, sintetizar e questionar, ampliando seu desenvolvimento cognitivo, e criando possibilidades para a libertação das amarras sociais impostas pela lógica estrutural da sociedade excludente. 
Apresentada a proposta, buscamos desenvolvê-la a partir de uma abordagem qualitativa no tratamento da questão, por meio de um estudo bibliográfico, com o objetivo de discutir sobre a modalidade Educação Especial no contexto da educação inclusiva, apontando para possibilidades de articulações pedagógicas no ensino e aprendizagem de crianças com deficiências.

\section{A Educação Especial na sociedade inclusiva: uma breve apresentação do tema}

Um dos pressupostos básicos para que a escola promova um ensino inclusivo, baseado em concepções e paradigmas que valorizem e respeitem as singularidades dos sujeitos da aprendizagem é o entendimento do que significa Educação Especial e Educação Inclusiva, considerando-se as principais relações, diferenças e articulações que esses termos assumem dentro do campo teórico-conceitual em que estão imersos; e considerando-se ainda, que "mudanças na terminologia são necessárias para refletir as mudanças políticas e práticas; - um exemplo específico é a mudança de "especial" para "inclusiva"”, conforme propõe a Declaração de Salamanca (1994, p. 32).

No quadro abaixo, Noronha; Pinto (2011, p. 04) sintetizam este entendimento, quando apontam para algumas "aproximações e convergências" entre os termos:

Quadro 01: Educação especial e educação inclusiva: aproximações e convergências

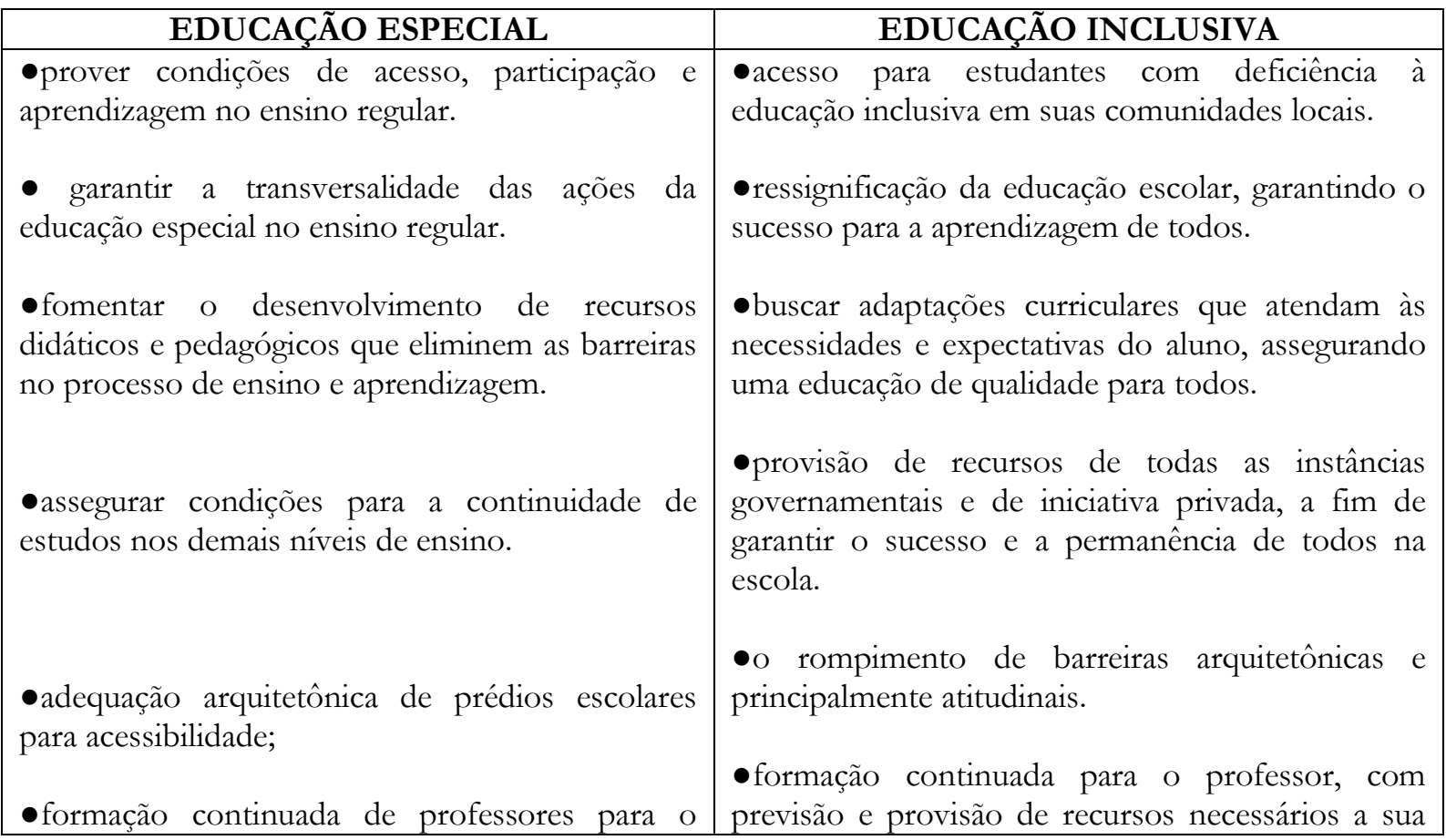




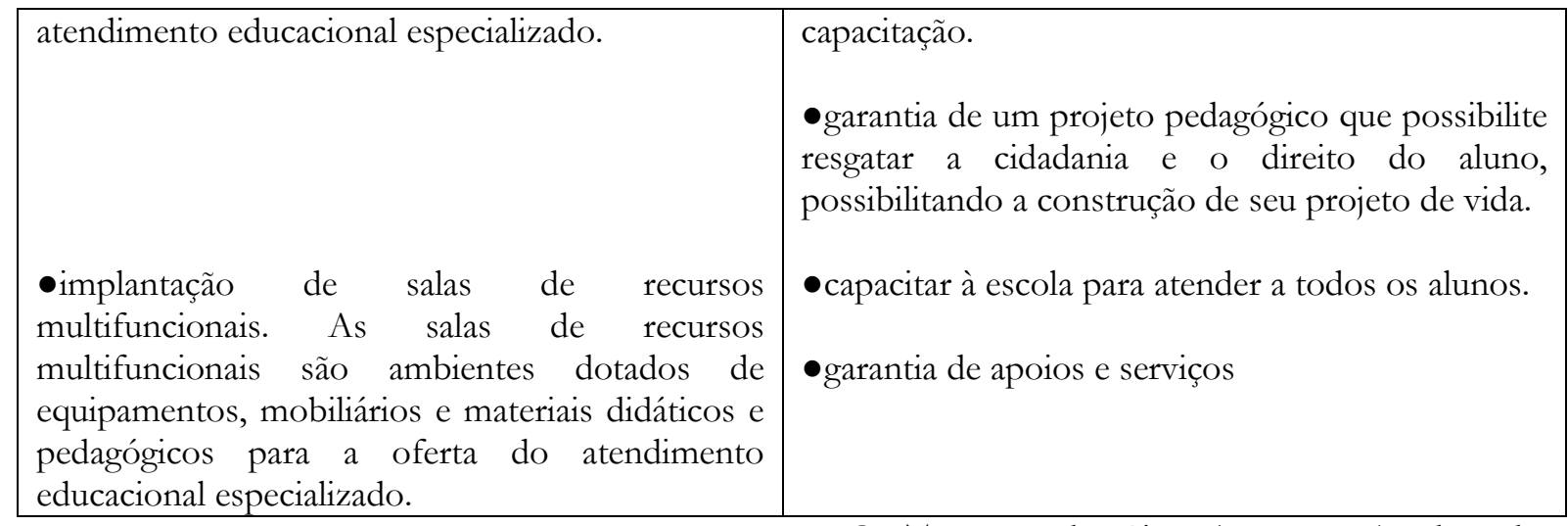

FONTE: Noronha; Pinto (2011, p. 04) [adaptado].

No âmbito legal e pedagógico, para que se entenda melhor o significado da Educação Especial, é necessário situar os níveis e modalidades de educação escolar. Na estrutura do sistema educacional brasileiro, conforme a LDB, compreendem-se como níveis, a Educação Básica e o Ensino Superior; e a modalidade é como o indivíduo poderá receber a formação dentro da Educação Básica, que se subdivide em: Educação Infantil, Ensino Fundamental e Ensino Médio. "Ela pode ser oferecida no ensino regular e nas modalidades de educação de jovens e adultos, educação especial e educação profissional, sendo que esta última pode ser também uma modalidade da educação superior” (OEI, s/d, p. 35).

De acordo com as Diretrizes Nacionais para a Educação Especial na Educação Básica (2001), essas modalidades educacionais devem se organizar no espaço escolar por meio de processos educacionais próprios, definidos em uma proposta pedagógica, que visa assegurar um conjunto de recursos e serviços educacionais especiais, organizados institucionalmente para apoiar, complementar, suplementar e, em alguns casos, substituir os serviços educacionais comuns, de modo a garantir a educação escolar e promover o desenvolvimento das potencialidades dos educando. De tal modo, para Ferreira, pode-se considerar que a Educação Especial:

[...] abrange, como princípio, o conjunto de serviços educacionais não disponível nos ambientes sócio-educacionais "normais" ou "regulares". Ela visaria o atendimento e a promoção do desenvolvimento de indivíduos que não se beneficiariam significativamente de situações tradicionais de educação, por limitações ou peculiaridades de diferentes naturezas (FERREIRA, 1993, p. 17)

As crianças com deficiências a serem atendidos durante o processo educativo deverão ser aqueles que aparentemente apresentarem dificuldades e limitações durante os processos de aprendizagem propiciados pela escola. Quando se observar que esse sujeito não está acompanhando as atividades curriculares, como os demais alunos, é necessário averiguar as causas. Estas podem não estar vinculadas às causas orgânicas específicas, podem estar relacionadas às condições sociais e culturais do contexto, que algumas vezes limitam o aluno. 
Este poderá ter dificuldade no aprendizado em função da comunicação ou mesmo por outros fatores.

Há de considerar ainda nesse processo, os alunos que apresentam elevado grau de facilidade e desenvoltura no aprendizado, maior que os demais alunos, como são os casos dos alunos superdotados e com altas habilidades, para os quais também deverá haver ensino especial. Questão que a LDB foi muito nobre em acrescentar à Educação Especial, pois reconhece que a Educação Especial não é destinada somente para aqueles que apresentam dificuldades, diminuindo assim, parte dos preconceitos e discriminações.

Este é o verdadeiro significado da Educação Especial compreendida dentro da Educação Nacional, oportunizando condições para que todos os alunos tenham oportunidade de superar as barreiras sociais que muitas vezes, os impedem de ter acesso aos direitos sociais que assegurem sua cidadania e dignidade plena, em conformidade com o artigo 22 da LDB: "A educação básica tem por finalidades desenvolver o educando, assegurando-lhe a formação comum indispensável para o exercício da cidadania e fornecer-lhe meios para progredir no trabalho e em estudos posteriores".

Desse modo, muito mais que direito a exercer a cidadania; a Educação Especial está hoje presente em todas as Leis ${ }^{3}$ que estruturam a organização social do país e todos podem ter acesso a essas Leis, cumpri-las e fazê-las cumprir, com o intuito de superar os fatores que dificultam a aprendizagem e a inclusão dos alunos com NEE no contexto da escola regular.

\section{Fatores que dificultam o aprendizado do aluno com necessidade especial}

Um questionamento bastante discutido é: Todos os alunos com dificuldades no aprendizado seriam considerados deficientes? Essa visão positivista de homem, do mundo e da sociedade está ainda muito presente na educação atual, como consequência de teorias conservadoras, cujos princípios ligam-se a manutenção desse modelo de sociedade na qual estamos inseridos que selecionam as pessoas para excluí-las, uma vez que nossa sociedade funciona através de mecanismos discriminatórios de "coerção normalizadora e fabricação ininterrupta de desviantes" (WANDERLEY, 1999, p. 08).

A dificuldade em aprender refere-se às situações difíceis, ocasionadas por fatores individuais, como limitação física ou cognitiva; ou fatores sociais, como falta de acessibilidade aos espaços sociais; vivenciadas pela criança, adolescente ou adulto durante o processo de construção

\footnotetext{
${ }^{3}$ Essa orientação legal está organizada através de Diretrizes, Declarações, Pareceres, Decretos, entre outros diferentes tipos de documentos legais que arregimentam a discussão em âmbito nacional.
} 
do conhecimento. Essas dificuldades, muitas vezes, podem ser superadas com metodologias adequadas utilizadas pelos professores, outras vezes não, necessitando da ajuda de outros profissionais tanto da área da educação, como da saúde, constituindo assim, um campo interdisciplinar no processo de intervenção pedagógica, onde se situam, pedagogos, psicopedagogos, neuropsicopedagogos, psicólogos, assistentes sociais, médicos, fonoaudiólogos etc.

Essas dificuldades de aprendizagem são consideradas os "sintomas" e comportamentos específicos apresentados pelos sujeitos, e, portanto, é pela intensidade com que eles se apresentam e pela duração que eles têm na vida escolar que se faz necessária a busca das possíveis causas. Existem segundo Oliveira, vários fatores que podem desencadear as dificuldades de aprendizagem:

\begin{abstract}
Orgânicas: cardiopatias, encefalopatias, diferenças sensórias motoras, intelectuais, disfunção cerebral e outras enfermidades de longa duração. Psicológicas: desajustes emocionais provocados pela dificuldade que a criança tem de aprender, o que gera ansiedade, insegurança e auto-conceito negativo. Pedagógicas: métodos inadequados de ensino, falta de estimulação pela pré-escola dos pré-requisitos à leitura e a escrita, falta de percepção, por parte da escola, do nível de maturidade da criança, iniciando uma alfabetização precoce; relacionamento professor/aluno deficiente; não domínio do conteúdo e do método por parte do professor, atendimento precário das crianças devido à superlotação das classes. Sócio-culturais: falta de estimulação (criança que não faz a pré-escola e também não é estimulada no lar), desnutrição, privação cultural do meio, marginalização com dificuldades de aprendizagem pelo sistema de ensino comum (OLIVEIRA, 2013, p. 25). (Grifos nossos)
\end{abstract}

Detectar a causa que interfere no desempenho escolar, principalmente da criança, é fundamental para o seu bom rendimento escolar, desde que as causas sejam trabalhadas. Existem várias maneiras para se constatar uma dificuldade da criança em aprender, mas o ponto de partida é o próprio desempenho do aluno, uma vez que as dificuldades da aprendizagem apresentam características próprias, que requerem um estudo e intervenção, a fim de compreender as causas, as "raízes" do problema, que desvelarão os rumos e as prioridades de ações a serem tomadas para, então, melhorar o processo de ensino e aprendizagem, partindo do nível de aprendizagem em que o aluno está e lançando desafios que oportunizem condições para o seu desenvolvimento social e intelectual.

\title{
Construção uma sala inclusiva: intervenção pedagógica e estratégias metodológicas no atendimento a crianças com NEE
}

Depois de identificadas as dificuldades enfrentadas pela criança na escola, uma intervenção pedagógica deve ter como objetivos: prevenir e minimizá-las. Para tanto, é necessário 
que o professor tenha o conhecimento e domínio de diferentes métodos e formas de ensinar, levando em consideração as múltiplas dificuldades apresentadas em uma sala de aula heterogênea, em que cada criança já traz consigo uma convivência de mundo; - mundos diferentes.

A ação docente deve ser a mais dinâmica e próxima da realidade, fazendo com que teoria e prática se firmem e tenha sentido para a criança, de maneira articulada e simultânea, buscando através da exploração de diferentes atividades, desenvolver as habilidades necessárias, promovendo a descoberta e a inserção da criança no mundo, sem que sofra alguma marginalização social, tendo em vista que, a ideia de um ensino inclusivo em nossas escolas, parte, de imediato, do pressuposto de que:

Constitui verdade inquestionável o fato de que, a todo momento, as diferenças entre os homens fazem-se presentes, mostrando e demonstrando que existem grupos humanos dotados de especificidades naturalmente irredutíveis. As pessoas são diferentes de fato, em relação à cor da pele e dos olhos, quanto ao gênero e à sua orientação sexual, com referência às origens familiares e regionais, nos hábitos e gostos, no tocante ao estilo. Em resumo, os seres humanos são diferentes, pertencem a grupos variados, convivem e desenvolvem-se em culturas distintas. São então diferentes de direito. É o chamado direito à diferença; o direito de ser, sendo diferente (FERREIRA; GUIMARÃES, 2003, p. 37).

A escola regular, de qualquer nível ou modalidade de ensino, ao viabilizar a inclusão de alunos com necessidades especiais, deverá promover a organização de classes comuns e de serviços de apoio pedagógico especializados. Extraordinariamente, poderá promover a organização de classes especiais, para atendimento em caráter transitório.

Seguiremos agora com a definição dos serviços de apoio pedagógico especializados, que de acordo com as Diretrizes Nacionais para a Educação Especial na Educação Básica (2001) são:

Classes comuns: Serviço que se efetiva por meio do trabalho de equipe, abrangendo professores de classe comum e da educação especial, para o atendimento às necessidades educacionais especiais dos alunos durante o processo de ensino e aprendizagem. Pode contar com a colaboração de outros profissionais, como psicólogos escolares, por exemplo.

Salas de Recursos: serviço de natureza pedagógica, conduzido por professor especializado, que suplementa (no caso dos superdotados) e complementa (para os demais alunos) o atendimento educacional realizado em classes comuns da rede regular de ensino. Esse serviço realiza-se em escolas, em local dotado de equipamentos e recursos pedagógicos adequados às necessidades educacionais especiais dos alunos, podendo estender-se a alunos de escolas próximas, nas quais ainda não exista esse atendimento. Pode ser realizado individualmente ou em pequenos grupos, para alunos que apresentarem necessidades educacionais semelhantes, em horário diferente daquele em que frequentam a classe comum.

Itinerância: serviço de orientação e supervisão pedagógica desenvolvida por professores especializados que fazem visitas periódicas às escolas para trabalhar com alunos que apresentem necessidades educacionais especiais e com seus respectivos professores de classe comum da rede regular de ensino. 
Professores-intérpretes: são profissionais especializados para apoiar surdos, surdo-cegos e outros que apresentem sérios comprometimentos de comunicação e sinalização. (MEC/SEESP, 2001, p. 50)

Seguindo-se essas orientações, a escola será, efetivamente, um lugar certo para que a inclusão possa acontecer na vida do aluno, imprimindo um caráter valorativo e cidadão em seu processo de desenvolvimento social. Pela conjectura proposta, os alunos serão integrados às propostas pedagógicas do currículo básico, assistidos quando necessário pelo professor da educação especial e outros profissionais capacitados. Por isso, é fundamental também, que não somente o professor, mas toda a equipe da escola seja capacitada para promover situações que sejam favoráveis à valorização das identidades, das diferenças e por fim, de aprendizagens significativas, considerando-se que:

A inclusão de alunos com necessidades educacionais especiais em classes comuns de ensino regular, como meta das políticas de educação, exige interação constante entre professor da classe comum e os de serviços de apoio pedagógico especializado, sob pena de alguns educandos não atingirem rendimento escolar satisfatório (MEC/SEESP, 2001, p. 51).

Para a realização desse continuum interacional presente no ensino, é importante que todos os professores de Educação Especial e os que atuam em classes comuns tenham formação para as respectivas funções, principalmente os que atuam em serviços de apoio pedagógico especializado. De acordo com Batista:

A formação continuada de professores é mais uma estratégia fundamental para atualização e aprofundamento do conhecimento pedagógico comum e especializado. Esta formação, preferencialmente acontecerá, a partir dos próprios casos de atendimento, pois esse é um material vivo, que propicia uma visão subjetiva que o professor responsável pela sala de aula ou por esse atendimento terá para dar conta da complexidade dos alunos e do seu processo de aprendizagem (BATISTA, 2006, p. 27).

No cerne da efetivação dessas práticas, situa-se Atendimento Educacional Especializado (AEE), como uma proposta de legitimação da inclusão na escola. As atividades desenvolvidas no espaço objetivam orientar a aprendizagem, por meio da ratificação, elaboração e organização de recursos que eliminam as barreiras para a plena participação dos alunos, e desenvolva autonomia e independência escolar e fora dela. É uma oferta obrigatória pelos sistemas de ensino e deve ser realizado obrigatoriamente em turno inverso ao da classe comum que o aluno está matriculado.

Conta-se nesse trabalho, com diferentes recursos multifuncionais, aproveitando-se de suas funcionalidades pedagógicas, uma vez que são essencialmente mediadores do conhecimento, possibilitando uma efetiva relação pedagógica de ensino e aprendizagem. Para Ropoli:

O AEE complementa e/ou suplementa a formação do aluno, visando a sua autonomia na escola e fora dela, constituindo oferta obrigatória pelos sistemas de ensino. É realizado, de preferência, nas escolas comuns, em um espaço físico denominado Sala de 
Recursos Multifuncionais. Portanto, é parte integrante do projeto político pedagógico da escola (ROPOLI, 2010, p. 17).

Importante esclarecer ainda, que o apoio proposto nas salas de AEE não constitui um reforço escolar, mas um serviço de educação especial, que "identifica, elabora e organiza recursos pedagógicos e de acessibilidade, que eliminem as barreiras para a plena participação dos alunos, considerando suas necessidades específicas" (SEESP/MEC, 2008, p. 15), desenvolvido a partir das habilidades dos alunos, portanto não há a obrigatoriedade de tarefas específicas. No intuito de compreender as principais dificuldades dos alunos, com as quais a escola se depara, o AEE, pode ser compreendido ainda, conforme Batista como:

[...] uma nova proposta, que marca uma grande virada no entendimento que a educação Especial propiciará em favor da inclusão, em todos os níveis de ensino. [...] garante a inclusão escolar de alunos com deficiência, na medida em que lhes oferece o aprendizado de conhecimentos, técnicas, utilização de recursos informatizados, enfim tudo que difere dos currículos acadêmicos que ele aprenderá nas salas de aula das escolas comuns. Ele é necessário e mesmo imprescindível, para que sejam ultrapassadas as barreiras que certos conhecimentos, linguagens, recursos representam para que os alunos com deficiência possam aprender nas salas de aulas comuns do ensino regular. Portanto, esse atendimento não é facilitado, mas facilitador, não é adaptado, mas permite ao aluno adaptar-se às exigências do ensino comum, não é substitutivo, mas complementar ao ensino regular (BATISTA, 2006, p. 26).

Dessa forma, a inclusão escolar refere-se ao processo de educar/ensinar, no mesmo grupo, crianças com ou sem NEE, durante parte ou totalidade do tempo. A proposta do AEE age no sentido de assegurar um ensino de qualidade, garantindo o acesso e a permanência dos alunos na escola, formando cidadãos críticos capazes de agir na transformação da sociedade.

\section{Considerações Finais}

No desenvolvimento deste trabalho abordou-se uma discussão sobre a Educação Especial, como modalidade de educação escolar situada em um contexto de sociedade inclusiva. O conceito de educação inclusiva não se restringe apenas aos portadores de necessidades especiais e sim a participação de todos os indivíduos nesse processo de construção do conhecimento, portanto, o objetivo da escola a qual se propõe é o acesso e garantia dos alunos com ou sem necessidades especiais.

As dificuldades de aprendizagem enfrentadas por crianças com NEE apresentam-se como um sintoma constante e real no quadro da educação brasileira, que toma cada vez maiores dimensões e acentuadas discussões nas pautas de reuniões e planejamentos de ações educativas e escolares, visto que a sociedade precisa estar atenta e acolher com respeito e maturidade esta nova demanda socioeducativa. Isto só será possível, mediante uma intervenção pedagógica 
eficiente que faça do ensino uma proposta inovadora, com sentido e significado social na vida das crianças que apresentam alguma dificuldade.

Consideramos, a partir disso, que todo aluno que apresenta alguma deficiência tem o direito e o dever de frequentar a escola regular; estudar com os demais; participar, em horários contrários aos seus, de atividades educativas em salas de recursos e caso haja necessidade mais acentuada e tendo as salas especiais, participar também destas, a fim de melhorar seu desempenho e a percepção crítica sobre a realidade em que está inserido.

É comum ouvirmos os professores citarem que cada vez mais se torna difícil trabalhar com alunos que apresentam NEE. Sabe-se que todos os sujeitos envolvidos no processo de inclusão, gestores, professores, funcionários, família e comunidade, são de fundamental importância para a construção de uma escola inclusiva, entretanto, na prática, muitas vezes, não é exatamente o que acontece. Muitas vezes, dentro das salas de aula, ainda vemos os sujeitos com dificuldades de aprendizagem mais acentuadas, sendo colocados em um lugar diferente dos demais colegas, demonstrando que a escola regular, ainda se sustenta em uma falsa ilusão sobre o que seja um ensino verdadeiramente inclusivo.

É, portanto, em revelia a esse discurso enraizado na cultura escolar, que firmamos a nossa discussão quando apontamos para a igualdade de possibilidades, como forma de promover a inclusão de todos e em todos os setores sociais, pensando na formação de um sujeito capaz de apreender o mundo em que vive em condições de transformá-lo e não somente de reproduzi-lo, e essa formação perpassa pela obtenção de habilidades, atitudes e valores, muitos deles, ensinados na escola.

\section{REFERÊNCIAS:}

BATISTA, Cristina Abranches Mota. Educação Inclusiva: atendimento educacional especializado para deficiência mental. 2 ed. Brasília: MEC/ SEEP, 2006.

BRASIL. Lei de Diretrizes e Bases da Educação Nacional. Lei n. 9.394, de 20 de dezembro de 1996.

Ministério da Educação. Diretrizes Nacionais para a Educação Especial na Educação Básica. Secretaria de Educação Especial. Brasília: MEC; SEESP, 2001.

. Ministério da Educação. Inclusão. Política Nacional de Educação Especial na Perspectiva da Educação Inclusiva. Secretaria de Educação Especial, v. 04. n. 05. Brasília: SEESP, 2008

CARVALHO, Rosita Edler. Removendo barreiras para a aprendizagem. Porto Alegre: Mediação, 2003. 
DECLARAÇÃO DE SALAMANCA: Sobre Princípios, Políticas e Práticas na Área das Necessidades Educativas Especiais. Salamanca-Espanha, 1994.

FERREIRA, J. R. A exclusão da diferença. Piracicaba: UNIMEP, 1993.

FERREIRA, M. E. C.; GUIMARÃES, M. Educação inclusiva. Rio de Janeiro: DP \& A, 2003.

MULLER, Pierre; SUREL, Ives. Análise das políticas públicas. Pelotas: EDUCAT, 2002.

NORONHA, Eliane Gonçalves; PINTO, Cibele Lemes. Educação Especial e Educação Inclusiva: aproximações e convergências. 1-9 p. Publicado em 2011. Disponível em: < http://www.catolicaonline.com.br/semanapedagogia/trabalhos completos/EDUCA $\%$ C3\% $\% 7 \%$ C3\%83O $\% 20$ ESPECIAL $\% 20 \mathrm{E} \% 20 \mathrm{EDUCA} \% \mathrm{C} 3 \% 87 \% \mathrm{C} 3 \% 83 \mathrm{O} \% 20$ INCLUSIVA\%20APROXIMA $\%$ C3\%87\%C3\%95ES\%20E $\% 20$ CONVERG $\%$ C3\%8ANCIAS.pdf $>$ Acesso em: 04 abr. 2014.

OEI. ESTRUTURA GERAL DO SISTEMA EDUCACIONAL. Sistema Educativo Nacional de Brasil. s/d, p. 35-41. Disponível em: < http://www.oei.es/quipu/brasil/estructura.pdf $>$. Acesso em: 20 fev. 2016.

OLIVEIRA, M. K. de. Vygotsky: aprendizado e desenvolvimento, um processo sócio-histórico. São Paulo: Scipione, 1993.

ROPOLI, Edilene Aparecida. A Educação Especial na Perspectiva da Inclusão Escolar: a escola comum inclusiva. Brasília: Ministério da Educação, Secretaria de Educação Especial; [Fortaleza]: Universidade Federal do Ceará, 2010.

WANDERLEY, Fabiana. Normalidade e patologia em educação especial. Psicologia. Ciência e Profissão, vol.19, n.2, pp. 2-9, 1999. Disponível em: < http://www.scielo.br/scielo.php?script $=$ sci arttext\&pid=S1414-98931999000200002 >. Acesso em: 22 fev. 2016. 